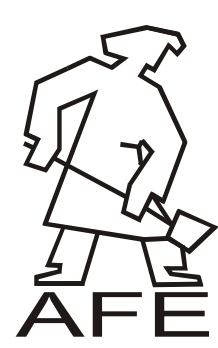

\title{
Casting Ductile Iron in Layer Moulds Made from Ecological Sands
}

\author{
M. Rączka ${ }^{\mathrm{a} *}$, K. Gandurski ${ }^{\mathrm{b}}$, B. Isendorf ${ }^{\mathrm{c}}$ \\ ${ }^{a}$ Chair of Production Process Engineering, Cracow University of Technology, al. Jana Pawła II 37, 31 -864 Cracow, Poland \\ ${ }^{\mathrm{b}}$ Hardtop Foundry, Charsznica, Poland \\ ${ }^{\mathrm{c}}$ Hardtop Foundry, Charsznica, Poland \\ *Contact for correspondence: e-mail: mraczka@pk.edu.pl
}

Received 16.04.2012; accepted in revised form 02.07.2012

\begin{abstract}
The article contains the results of tests performed under the target project in Hardtop Foundry Charsznica.

The objective of the tests and studies was to develop a technology of making high-quality ductile iron castings, combined with effective means of environmental protection. The studies presented in this article related to castings weighing from 1 to $300 \mathrm{~kg}$ made from ductile iron of grades 400-15 and 500-7, using two-layer moulds, where the facing and core sand was the sand with an alkaline organic binder, while backing sand was the sand with an inorganic geopolymer binder.

A simplified method of sand reclamation was applied with possible reuse of the reclaim as an addition to the backing sand. The cast iron spheroidising treatment and inoculation were selected taking into account the specific conditions of Hardtop Foundry. A pilot batch of castings was made, testing the gating and feeding systems and using exothermic sleeves on risers. The study confirmed the validity of the adopted concept of making ductile iron castings in layer moulds, while maintaining the content of sand with an organic binder at a level of maximum $15 \%$.
\end{abstract}

Keywords: Innovative foundry materials and technologies, Environmental protection, Ductile iron, Two-layer moulds, Casting examinations

\section{Introduction}

Studies presented in this paper were conducted under the target project in Hardtop Foundry Charsznica. The purpose of the industrial research and of the development, implementation and investment works was:

— to choose the self-setting sand technology and develop the composition of moulding and core sands for the range of ductile iron castings manufactured by HARDTOP Foundry,

- to develop a technology for making castings from the implemented materials,

- to design a work post for the manufacture of moulds and cores from self-setting sands, for metal melting, and for knocking out and fettling of castings,

- to start the production of responsible castings made from ductile iron with improved strength properties and performance characteristics.
Making castings from ductile iron is a difficult task because it is necessary to adjust and combine into one whole a set of the following counteracting elements $[1,2,3,4,5]$ :

- the mass density of magnesium is four times lower than that of the liquid cast iron. Therefore it is necessary to use special methods for immersion of magnesium and keeping it under the melt surface,

- the boiling point of magnesium is $1105^{\circ} \mathrm{C}$, and so it is much lower than the temperature of the overheated liquid cast iron, having high affinity to oxygen, magnesium shall enter into reaction with oxides present in the melt and by reducing them shall lower its own content in the cast iron.

The rate of magnesium loss in cast iron depends on several factors, like the temperature of metal, oxygen availability, contact with the slag, the ladle lining material, and the atmosphere. 
Based on the results of the tests carried out it has been found that any transfer of metal from one vessel to another after the spheroidising treatment will cause a 0.007 to $0.01 \%$ drop in magnesium content; holding of the melt in a ladle results in a magnesium loss of about $0.001 \% / \mathrm{min}$.

Magnesium never dissolves completely in cast iron, and this limited solubility depends on the chemical composition of cast iron, i.e. on the content of carbon, silicon, etc.

Various techniques are used to introduce magnesium to the cast iron melt and to eliminate the difficulties discussed above.

The dissolution of magnesium in liquid cast iron is also dependent on the time during which the bubbles of magnesium vapour are in contact with cast iron, and on the surface area of these bubbles, as expressed by the following equation:

$\mathrm{R}_{\mathrm{Mg}}=\mathrm{f}(\mathrm{T} ; \mathrm{F}) \quad[2,4]$

Achieving the highest possible value of the coefficient $R$ requires actions to ensure the longest possible time of contact between the cast iron melt and magnesium, which initially almost always occurs in gaseous form, and creating the largest possible surface area for contact between the cast iron and magnesium bubbles.

\section{Description of research methods}

\subsection{Choice of the cast iron spheroidising treatment and inoculation}

When evaluating various methods of spheroidisation to choose an optimum one for the specific needs and conditions of HARDTOP Foundry, besides the selection of equipment also the choice of a spheroidising agent was taken into account.

To ensure the longest possible time of contact between the cast iron and magnesium, the slender ladle with a removable lid was thought to be the best solution for the spheroidising treatment, considering also a relatively easy operation of the slag removal and pouring of moulds with metal.

The main objective of the chosen method was to reduce the volume of air available during the reaction of hot metal with magnesium alloy. The benefits of this method are as follows:

- reduced smoke and glare effect,

— increased magnesium yield,

- reduced loss of temperature,

_ improved compatibility in the final content of magnesium.

\subsection{Moulding and core sand technology}

In HARDTOP Foundry, castings from iron alloys were previously done manually in common bentonite sands and in the $\mathrm{CO}_{2}$-hardened loose self-setting sands with water glass 145 . Yet, sands with water glass hardened with $\mathrm{CO}_{2}$ are characterised by rather poor knocking out properties, and the addition of binder is relatively large [6]. The surface quality of castings made in the sand moulds with water glass 145 has proved to be inadequate and failed to meet the customer requirements. In addition, sands with water glass were characterised by high hygroscopicity, which made long storing of cores and moulds impossible. The occasionally experienced friability of the sand increased the risk of casting defects in the form of sand inclusions. At the same time, too much of water glass added to the sand increased the moisture content in this sand and resulted in the occurrence of casting defects, mainly pores and occasionally in extreme cases also blowholes. In the periods of increased humidity of the atmospheric air, it was very difficult to maintain the technological regime in the foundry, and the increased friability of moulds finally resulted in an increased rate of the rejected castings.

Therefore it was decided to use in the process of making responsible ductile iron castings new types of the self-setting sands for both moulds and cores.

The first assumption was that ductile iron castings would be made in layer moulds.

It was decided to use for the facing and core sand a composition containing alkaline phenolic resin of the trade name Super Eco R. For the backing sand, a mixture containing alkaline geopolymer binder of the trade name Rudal A was selected. The use of two sands of the same chemical nature (highly alkaline) made combining them together relatively easy and facilitated the reclamation process. The sand was hardened by blowing it with carbonic acid anhydride - carbon dioxide.

\subsection{Simulation studies of selected ductile iron castings}

The simulation and respective calculations of the casting process were performed in a MAGMAsoft programme. The programme was provided with a specialised module called MAGMAIron used for an analysis of the cast iron solidification process [7]

The analysis of cast iron solidification and cooling was carried out, paying special attention to phenomena occurring at the level of microstructure and to the liquid/solid phase transition by nucleation and precipitation of primary austenite and a eutectic phase as a mixture of pearlite and cementite. Cooling rate was also taken into account as a primary factor which determines the stability and the number of nuclei on which the solid phase is formed and growing. The impact of the cooling rate on the size and distribution of graphite was also examined.

\section{Discussion of results}

\subsection{Simulation of the casting process}

The initial process conditions such as the alloy composition, mould material, pouring temperature, pouring time, and the heat transfer parameters in a mould-casting system were determined.

Table 1 gives the chemical composition of alloys analysed. 


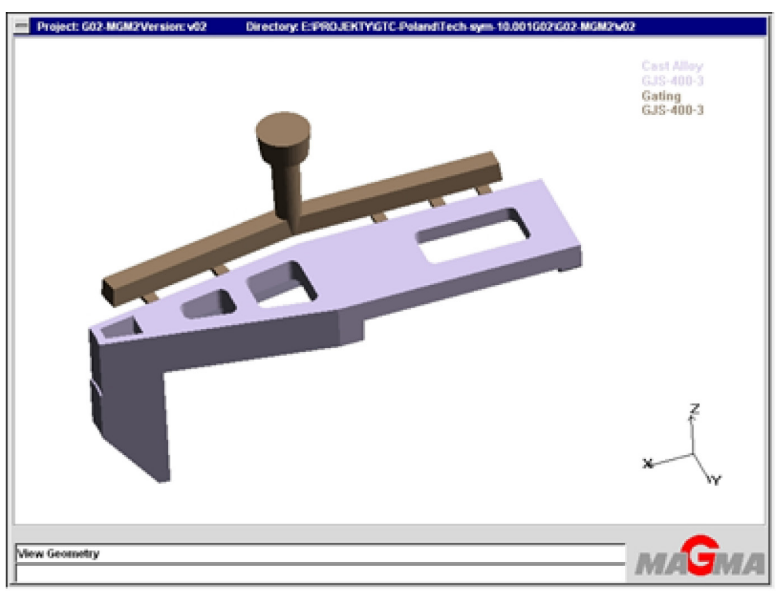

Fig. 1. The technology of making the casting of a base
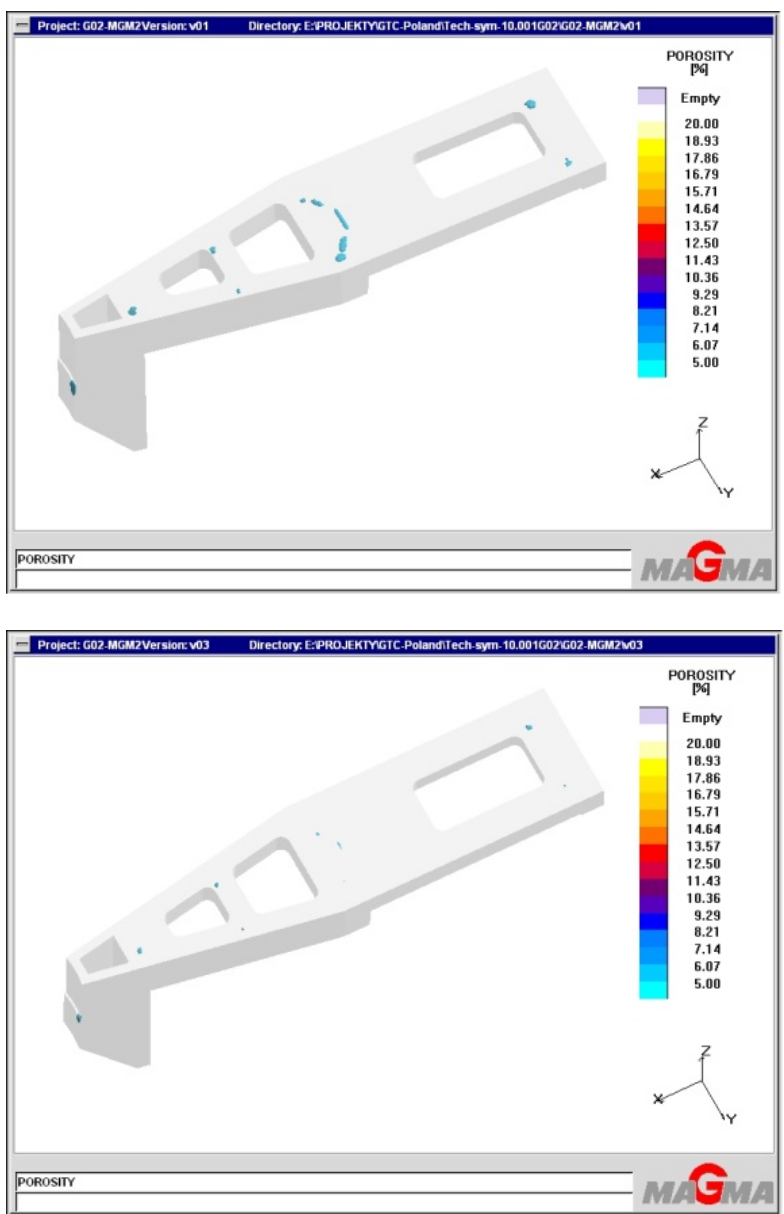

Fig. 2. The distribution of porosity above 5\% for compositions $\mathrm{S} 1$ and $\mathrm{S} 3$ given in Table 1
Table 1.

Chemical analysis of the examined alloys

\begin{tabular}{|l|l|l|l|l|l|l|l|}
\hline & C & Si & Mn & P & S & Cu & Mg \\
\hline S1 & 3,6 & 2,65 & 0,15 & 0,016 & 0,02 & 0,1 & 0,036 \\
\hline S2 & 3,3 & 2,65 & 0,15 & 0,016 & 0,02 & 0,1 & 0,036 \\
\hline S3 & 3,3 & 2,3 & 0,15 & 0,016 & 0,02 & 0,1 & 0,036 \\
\hline S4 & 3,7 & 2,3 & 0,15 & 0,016 & 0,02 & 0,1 & 0,036 \\
\hline
\end{tabular}

Example of analysis for the casting of a base:

Weight $-102 \mathrm{~kg}$

Cast iron - GJS400-15

Pouring temperature $-1310^{\circ} \mathrm{C}$

Number of active nuclei $-100 \%$

Graphitisation ratio - good ( 7 in a 1 to 10 scale)

Inoculation process - good
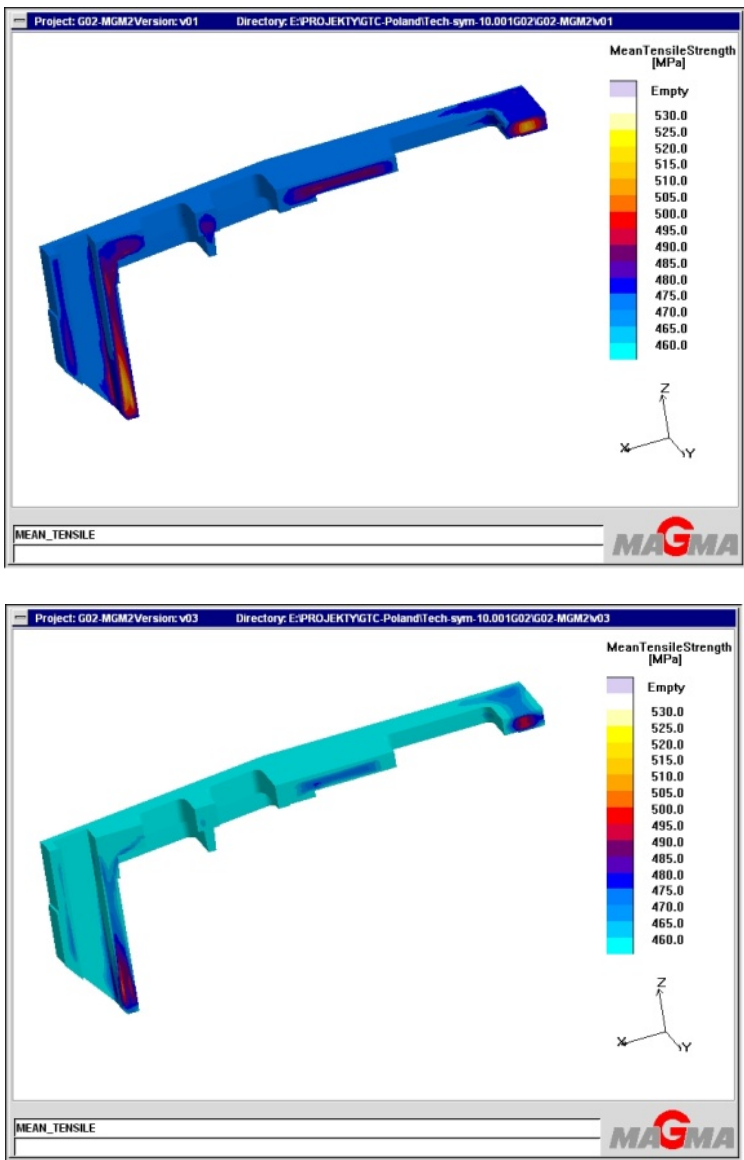

Fig. 3. The distribution of tensile strength values in casting cross-section for different compositions

The applied casting technology is shown in Figure 1. Metal is poured into the mould cavity through five ingates. The adopted time of pouring is 12 seconds and the pouring temperature is $1310^{\circ} \mathrm{C}$. Figures 2 and 3 show the results of calculations of the porosity level and tensile strength values distribution.

From the performed calculations it follows that the porosity can be minimised by the properly adjusted chemical composition 
and properly conducted metallurgical process. The analysis shows that to obtain a porosity of less than $5 \%$, the best composition is the composition No. S3 (Table 1).

\subsection{The choice of basic moulding and core sand components}

Layer moulds were made from sands hardened by blowing with carbon dioxide - $\mathrm{CO}_{2}$. The facing and core sand contained in its composition an organic binder, which was the Super Eco R alkaline phenolic resin, while backing sand contained an alkali geopolymer binder called Rudal A.

The sand mixtures were prepared in batch type wing mixers.

Tests were conducted using newly developed pattern equipment. The results of the tests and trials enabled optimising the technology of casting production in different sectors of the casting stand, i.e. to synchronise the following technological operations: preparation of moulding and core sands, making moulds and cores, pouring of castings, cooling of castings and knocking out.

The test moulds and cores for pilot castings were made from the following sands:

- facing and core sand with an alkaline organic binder Super Eko R,

- backing sand with an inorganic geopolymer binder RUDAL A.

Studies to select the best composition of the facing and backing moulding sand and of the core sand were carried out on the following materials:

- silica sand from Grudzień Las

- main fraction $0,40 / 0,32 / 0,20-91,31 \%$

- dust fraction content $(<0,100 \mathrm{~mm})-0,36 \%$

- clay content $<0,2 \%$

- sintering point $>1350^{\circ} \mathrm{C}$

- moisture content - $0,03 \%$

$\cdot \mathrm{pH}-6,70$

- specific surface area - $6,02 \mathrm{~m}^{2} / \mathrm{kg}$

- RUDAL A binder

- sodium silicate content $\left(\mathrm{Na}_{2} \mathrm{O}+\mathrm{SiO}_{2}\right)-40 \div 46 \%$

- $\mathrm{pH} 12,5 \div 13,5$

- SUPER EKO R binder

- viscosity at $20^{\circ} \mathrm{C}-170 \div 320[\mathrm{cP}]$

- density at $20^{\circ} \mathrm{C}-1,280-1.330\left[\mathrm{~g} / \mathrm{cm}^{3}\right]$

The composition of the facing and core sand was as follows (in parts by weight):

- silica sand from Grudzień Las $\quad-100$

- Super Eko R binder $\quad-2$

- hardening with $\mathrm{CO}_{2} \quad-15 \mathrm{sec}$

The sand properties were as follows:

- compression strength (measured after $1 \mathrm{~h}, 3 \mathrm{~h}$ and $24 \mathrm{~h}$ of hardening )

Rc1h $1,2 \div 1,35 \mathrm{MPa}$

Rc3h $1,45 \div 1,7 \mathrm{MPa}$
Rc24h $2,0 \div 2,55 \mathrm{MPa}$

- bending strength

Rg1h $0,85 \div 1,15 \mathrm{MPa}$

Rg3h $1,2 \div 1,35 \mathrm{MPa}$

$\operatorname{Rg} 24 \mathrm{~h} \quad 1,8 \div 2,1 \mathrm{MPa}$

- permeability after $24 \mathrm{~h}$

PS24h $>600 \mathrm{~m}^{2} / \mathrm{Pa} \cdot \mathrm{S}$

The composition of the backing sand was as follows (in parts by weight):

- silica sand from Grudzień Las - 100

- Rudal A binder $\quad-2,5 \div 3,0$

- hardening with $\mathrm{CO}_{2} \quad-15 \mathrm{sec}$

The sand properties were as follows:

- compression strength

$\begin{array}{lrl}\text { Rc1h } & 0,75 & \div 1,15 \mathrm{MPa} \\ \text { Rc3h } & 1,1 & \div 1,4 \mathrm{MPa} \\ \text { Rc24h } & 1,7 & \div 1,95 \mathrm{MPa}\end{array}$

- permeability after $24 \mathrm{~h}$

$\mathrm{PS} 24 \mathrm{~h}>550 \mathrm{~m}^{2} / \mathrm{Pa} \cdot \mathrm{S}$

\subsection{Mould making}

Moulds for pilot castings were made from the facing sand with a Super Eco R organic binder and from the backing sand with a Rudal A inorganic geopolymer binder. Like facing sand, the core sand was also prepared with a Super Eco R binder.

Moulds and cores were compacted manually with rammers. Hardening of moulds and cores was performed by blowing them with carbon dioxide for $30 \sim 90$ seconds, depending on the mould size. Patterns were withdrawn from moulds after the sand hardening. The quality of moulds and cores was good. After the lapse of 4 to 6 hours from the moulding operation, both moulds and cores were coated with protective coatings based on alcohol.

After thorough mixing, the protective coatings were applied with brush. Cores were placed in moulds and moulds were assembled when totally cooled from the operation of firing the protective coating. In justified cases, to ensure proper feeding of casting and to reduce the amount of liquid metal necessary for one cast element, risers in exothermic sleeves were used. Exothermic sleeves of the trade names Volmix T EXP-AXT and Volumix M FXM-AXM were made by Jodovit Chemical Group. Risers were not used when castings of similar wall thickness and free from the hot spots were made. The high rigidity of moulds made from the implemented sands enabled using the self-feeding technique, but then it was necessary to strictly observe the recommended technological regime in respect of:

- chemical composition of metal,

- pouring temperature,

- mould making technology,

- metal processing technology.

The technique of self-feeding was applied in the manufacture of the aforementioned pilot castings. 
Moulds for these castings were assembled in the moulding shop and poured with molten iron in $9-10$ hours after moulding.

\subsection{Melting of cast iron and pouring of moulds}

The cast iron had the following composition:

Ductile iron EN - GJS - $400-15$

$\begin{array}{ll}\mathrm{C} & 3,3 \\ \mathrm{Si} & 2,3 \\ \mathrm{Mn} & 0,5 \\ \mathrm{P} & 0,015 \\ \mathrm{~S} & 0,005 \\ \mathrm{Mg} & 0,015\end{array}$

From the test ingots, specimens for mechanical testing were prepared by machining; polished sections were also made for structure examinations.

The mechanical properties of EN - GJS - 400 - 15 cast iron were as follows:

$$
\begin{array}{ll}
\cdot \text { Rm } & 480-535 \mathrm{MPa} \\
\cdot \text { Re } & 360-389 \mathrm{MPa} \\
\text { - A5 } & 14,8-16,8 \%
\end{array}
$$

The ready casting of a base is shown in Figure 4

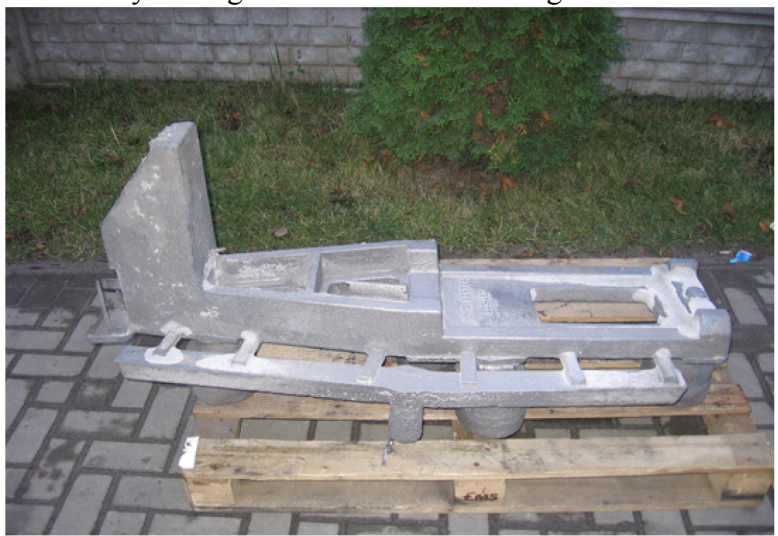

Fig. 4. Casting of the base weighing $102 \mathrm{~kg}$. GJS 400-15

\section{Conclusions}

The technological tests of making responsible ductile iron castings in layer moulds from sands with alkaline binders and studies of the properties of cast materials and ready castings fully confirmed the validity of the adopted concept and technology.

Using two types of sand for the manufacture of moulds and cores, i.e.:

- core and facing sand with a Super Eco R phenolic resin, and

- backing sand with a Rudal A geopolymer binder

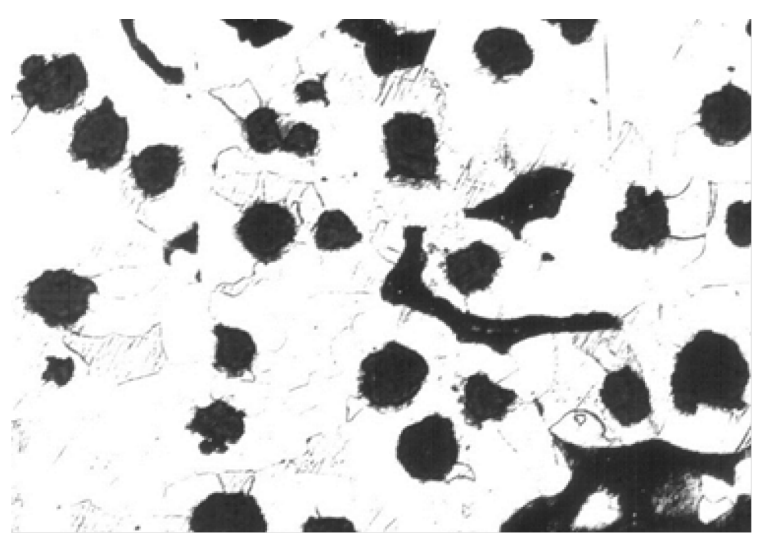

Fig. 5. Cast iron of EN-GJS-400-15 grade. Ferritic structure with small amount of pearlite P6, etched with Mi 1 Fe, 100x

- contributed to an improvement of the casting quality and considerably facilitated the production process due to:

- better knocking out properties of the sand,

- less strenuous work with the casting cleaning and finishing,

- reduced waste owing to a simplified sand reclamation process.

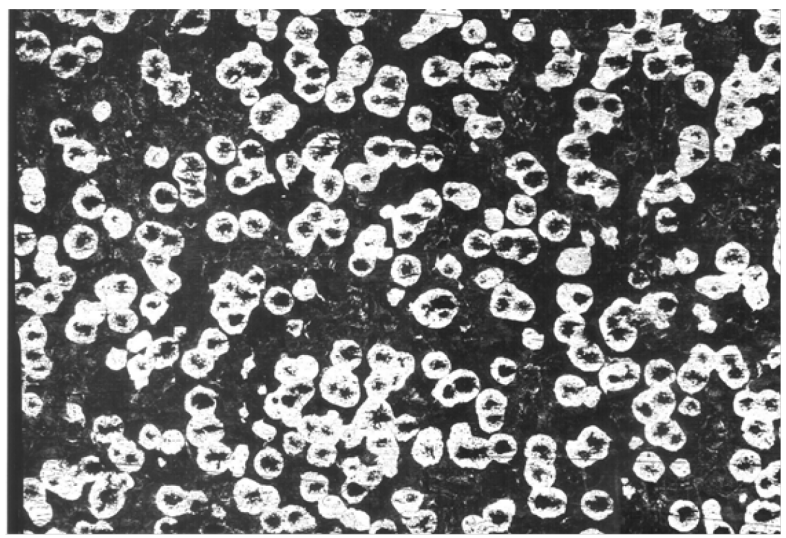

Fig.6. Cast iron of EN-GJS 500-7 grade. Pearlitic-ferritic structure P70, etched with Mi1Fe. 100x

The new technology has allowed the commercial production of new materials and casting types not manufactured so far by this Foundry.

At the same time, as a result of the new technology being implemented to production, other benefits followed to mention only:

- reduced level of rejects

- reduced level of molten metal consumption due to the use of risers with exothermic sleeves. 
The technology of layer moulds used by HARDTOP Foundry has greatly contributed to raising the technical level of the foundry and increasing its competitiveness against other manufacturers of castings.

\section{References}

[1] Fraś, E. \& Podrzucki, C. (1978). Żeliwo modyfikowane. Skrypt uczelniany AGH. Kraków.

[2] Karsay, S.I. (2000). Żeliwo sferoidalne $i$ wytwarzanie. Tłumaczenie wydania polskiego M. Kaczorowski, Warszawa.
[3] Piaskowski, J. (1986). Żeliwo sferoidalne. Poradnik dla odlewnika. Wydanie Instytutu Odlewnictwa w Krakowie.

[4] Sorelmetal: O żeliwie sferoidalnym.

[5] Tabor, A., Rączka, J. (1996). Odlewnictwo. FOTOBIT, Kraków.

[6] Lewandowski, L. (1991). Masy formierskie i rdzeniowe. Wydawnictwo Naukowe PWN, Warszawa.

[7] Gwiżdż, A., Pysz, S. \& Dworak, P. (2010). MAGMAsoft simulation applied in verification of technology to produce new range alloy steel castings. Archives of Foundry Engineering. Vol. 10, Issue 3, July-September 2010. Polish Academy of Sciences. Katowice-Gliwice.

[8] Tabor, A. (2007). Odlewnictwo. Politechnika Krakowska. Kraków. 